\title{
Recovery temperatures of defects in tungsten created by self-implantation
}

\author{
E. Markina, M. Mayer*, A. Manhard and T. Schwarz-Selinger \\ Max-Planck-Institut für Plasmaphysik, Boltzmannstr. 2, 85748 Garching, Germany
}

\begin{abstract}
The recovery of radiation defects in recrystallized tungsten was studied in the temperature range $400-1150 \mathrm{~K}$. The defects were created by $20 \mathrm{MeV}$ tungsten ions irradiation at room temperature to a maximum damage level of $0.9 \mathrm{dpa}$. The samples were then annealed to temperatures of 400 to $1150 \mathrm{~K}$ for 1 hour in order to anneal the created defects. After annealing the remaining defects were decorated with $\mathrm{D}$ by exposing them to a lowtemperature ECR-plasma at $400 \mathrm{~K}$ to a fluence of $1 \times 10^{25} \mathrm{D} / \mathrm{m}^{2}$. Deuterium was detected by nuclear reaction analysis and temperature programmed desorption. Annealing of defects is observed already at slightly elevated temperatures. At $820 \mathrm{~K}$ about $50 \%$ of the initial defects were annealed, while still about $30 \%$ of the initial defects were present after annealing at 1150 K.
\end{abstract}

PACS: 52.40.Hf; 52.77.Dq; 61.80.Jh; 61.82.Bg

PSI keywords: Materials properties; Neutron damage; Retention; Surface analysis; Tungsten

*Corresponding author address: Max-Planck-Institut für Plasmaphysik, Boltzmannstr. 2, 85748 Garching, Germany

*Corresponding author E-mail: matej.mayer@ipp.mpg.de

Presenting author: Matej Mayer

Presenting author e-mail: matej.mayer@ipp.mpg.de 


\section{Introduction}

In future fusion devices tritium will be used as fuel for the fusion reaction. Its radioactivity raises a safety concern for the design of a fusion reactor in terms of retention properties of the plasma-facing materials. The first wall and divertor parts of a fusion reactor will be subjected to high fluxes of energetic charged particles, neutral atoms, and neutrons [1,2]. All these processes affect the hydrogen retention of the plasma-facing materials (PFMs).

Both for ITER and for future fusion power reactors like DEMO tungsten has been suggested as a possible divertor material due to its favorable properties, such as high thermal conductivity, high melting temperature, low sputtering yield and low hydrogen isotope retention. However, in ITER and DEMO the first wall materials will be subjected to high neutron fluxes originating from the D-T nuclear reaction. Besides significant changes in mechanical properties neutron irradiation affects also hydrogen isotope retention in the firstwall materials.

Fast fusion neutrons result in displacement damage, transmutation of tungsten to rhenium and osmium, and gas production. Radiation damage by neutrons can increase the hydrogen isotope retention in tungsten considerably. For ITER the neutron damage of tungsten will remain below $1 \mathrm{dpa}$ at the end of the operational period, while for DEMO a damage level of 15 dpa after one full power year is predicted in recent calculations by Gilbert et al. [2].

The hydrogen retention behavior of tungsten under neutron bombardment is often being investigated by using tungsten self-implantation as a proxy for neutrons. Self-implantation by tungsten ions has the advantages to be fast, to avoid activation of the sample, and to avoid the introduction of additional impurities which potentially may act as additional trap sites for hydrogen. But it should be kept in mind that tungsten self-implantation mimics neutron effects only to some extend: The maximum primary knock-on atom (PKA) energies and the damage rates are generally higher than by neutrons, while the PKA energy spectrum is softer 
[3]. The influence of these similarities and differences on radiation damage and hydrogen retention in tungsten is topic of active research. Tungsten self-implantation creates various types of radiation defects, especially interstitials, vacancies, vacancy clusters, and dislocations [4]. Hydrogen retention increases to levels of more than $1 \% \mathrm{H} / \mathrm{W}$ at around room temperature at damage levels of $0.5 \mathrm{dpa}$ and above $[5,6,7,8]$.

Radiation defects created at lower temperatures can be annealed at elevated temperatures and some recovery of the original material structure can be achieved. In this work the annealing of defects is determined by decorating the defects with deuterium. The defects were created at room temperature.

\section{Experimental}

The samples were made from polycrystalline hot rolled tungsten manufactured by Plansee SE, Austria, with a purity of 99.97 at.\%. All samples were cut from one manufacturing batch [9]. The samples with sizes $12 \mathrm{~mm}$ by $15 \mathrm{~mm}$ and $0.8 \mathrm{~mm}$ thick were mechanically polished using sand papers with decreasing grain sizes and finally with diamond powders down to diamond grain sizes of $0.032 \mu \mathrm{m}$ until mirror finish [10]. After polishing the samples were recrystallized at $2000 \mathrm{~K}$ for $10 \mathrm{~min}$ in vacuum at a base pressure $<10^{-5} \mathrm{~Pa}$ in order to anneal surface defects introduced by the polishing process and in order to achieve a very low residual defect level throughout the sample [9]. W implantations were performed at a $3 \mathrm{MV}$ tandem accelerator laboratory on a water cooled substrate holder. For homogeneous implantation the $\mathrm{W}$ ion beam was scanned over the whole sample surface. $\mathrm{W}^{6+}$ ions with an energy of $20 \mathrm{MeV}$ were used at an implantation fluence of $1.4 \times 10^{18} \mathrm{~m}^{-2}$. According to SRIM 2008 calculations $[11,12]$ the damage profile extends to a depth of $2.3 \mu \mathrm{m}$ at this energy, see Fig. 1 . The "full cascade option", a displacement energy of $90 \mathrm{eV}$ [13], and theoretical tungsten density were used. The total number of vacancies counted by SRIM was assumed as displacements per 
atom (dpa). With these assumptions the implanted fluence converts to 0.9 dpa in the damage peak, the damage depth profile is shown in Fig. 1.

After damaging the samples were post-annealed in a high vacuum oven for $5-300$ minutes at the desired post-annealing temperature in vacuum at a pressure $<10^{-4} \mathrm{~Pa}$, the set temperature was reached with a heating ramp of $60 \mathrm{~K} / \mathrm{min}$.

The samples were loaded with deuterium at the ECR plasma device PlaQ [14]. Five samples were exposed simultaneously. The temperature of the samples was measured by an infrared camera and a thermocouple clamped to the sample holder. The sample temperature was kept at $400 \pm 10 \mathrm{~K}$ by a liquid thermostat using heated silicone oil during plasma loading at floating potential with an ion energy of around $15 \mathrm{eV}$. The particle flux consists mainly of $\mathrm{D}_{3}{ }^{+}$ with small fractions of $\mathrm{D}_{2}^{+}$and $\mathrm{D}^{+}$with a total $\mathrm{D}$ flux of $5 \times 10^{19} \mathrm{D} / \mathrm{m}^{2} \mathrm{~s}$ [14]. These low ion energies are well below the damage threshold value, so no damage is expected to be introduced into the near surface layer during the ion implantation. The implantation time was $48 \mathrm{~h}$ during which a $\mathrm{D}$ fluence of $1 \times 10^{25} \mathrm{D} / \mathrm{m}^{2}$ was accumulated. After implantation the samples cooled down to room temperature with an initial cooling rate of about $5 \mathrm{~K} / \mathrm{min}$.

After sample loading retained deuterium was determined by nuclear reaction analysis (NRA) using the $\mathrm{D}\left({ }^{3} \mathrm{He}, \mathrm{p}\right){ }^{4} \mathrm{He}$ and $\mathrm{D}\left({ }^{3} \mathrm{He},{ }^{4} \mathrm{He}\right) \mathrm{p}$ nuclear reactions. The protons were detected at a reaction angle of $135^{\circ}$ using a PIPS-detector with $2000 \mu \mathrm{m}$ depletion depth, a solid angle of $29.9 \mathrm{msr}$, and stopper foils of $5 \mu \mathrm{m} \mathrm{Ni}$ and $12 \mu \mathrm{m}$ Mylar. Seven different energies of the analysing ${ }^{3} \mathrm{He}^{+}$ion beam were applied, ranging from 500 to $4500 \mathrm{keV}$ to probe different sample depths [15]. At low energies the alphas were detected at a reaction angle of $102^{\circ}$ with a $700 \mu \mathrm{m}$ thick PIPS detector in order to achieve a good depth resolution in the near surface layer [16]. At energies of $1200 \mathrm{keV}$ and higher only protons were detected. Finally the spectra were deconvoluted using the NRADC [18] code with SIMNRA [19] as simulation kernel and using cross-section data from $[20,21]$ in order to obtain D depth profiles until a depth of 
$7.8 \mu \mathrm{m}$. Integration of these depth profiles over depth provides the amount of $\mathrm{D}$ within these $7.8 \mu \mathrm{m}$.

Total amounts of $\mathrm{D}$ retained in the samples were measured by temperature programmed desorption (TPD). These measurements were performed at the Thermal Effusion Spectroscopy Setup TESS [22]. The samples were installed in a glass tube at a base pressure of $10^{-7}-10^{-8}$ mbar during the heating ramp. A movable oven was used for sample heating at an oven heating ramp of $15 \mathrm{~K} / \mathrm{min}$ and a maximum oven temperature of $1323 \mathrm{~K}$. The oven temperature was feedback controlled with a thermocouple attached to the heating element, the sample temperature was calibrated versus the oven temperature using a thermocouple spot welded to a similar sample. The gas composition during the measurement was monitored by a Pfeiffer DMM 422 quadrupole mass spectrometer in multi ion detection mode, collecting mass channels from 2 to $48 \mathrm{amu} / \mathrm{q}$. After every TPD measurement a background run without sample was performed in order to control the residual background signals, especially the mass signals of $\mathrm{D}_{2}, \mathrm{HD}, \mathrm{D}_{2} \mathrm{O}, \mathrm{HDO}$. The signal of mass 3 (HD) was typically more than 2 orders of magnitude smaller compared with the mass $4\left(\mathrm{D}_{2}\right)$ signal and was neglected in the analysis.

\section{Results and discussion}

Tungsten samples were damaged at room temperature to a maximum damage level of 0.9 dpa and subsequently post-annealed to a given temperature in the range $550-1150 \mathrm{~K}$ for 1 hour. These damaged and annealed samples were then implanted with deuterium to a fluence of $10^{25} \mathrm{D} / \mathrm{m}^{2}$ at $400 \mathrm{~K}$ in order to decorate the remaining defects. The deuterium depth profiles are shown in Fig. 1 together with the calculated damage profile. The layer widths of the calculation were based on the achieved depth resolution in the corresponding depth based on RESOLNRA calculations [23]. 
The not annealed sample shows a maximum deuterium concentration of $1.6 \% \mathrm{D} / \mathrm{W}$. The thickness of the damaged layer agrees within the depth resolution of the method with the depth of the calculated damage profile. At depths larger than the damaged layer the concentration decreases to values below $0.01 \% \mathrm{D} / \mathrm{W}$. Pre-annealing of the sample reduces the deuterium concentration in the damaged layer, while the trapped deuterium remains constant within the uncertainty of the method at depths larger than the damaged layer.

The deuterium concentration in the damage peak as function of pre-annealing time is shown in Fig. 2 for the case of $820 \mathrm{~K}$ annealing. Already after an annealing time of $30 \mathrm{~min}$ the deuterium retention has decreased to a stable value, which does not change further even by annealing for 5 hours. The first data point after 5 minutes should not be over-interpreted, because for this short annealing time the ramp-up and cool-down times of the oven cannot be neglected.

The deuterium concentration in the damage peak and the total deuterium inventory in the damaged layer as derived from NRA are shown as function of the pre-annealing sample temperature in Fig. 3. The samples were pre-annealed for 1 hour at the given temperature. Although the damaging was performed at room temperature, the lowest temperature data point is shown at $400 \mathrm{~K}$ due to the deuterium implantation at this temperature: It cannot be excluded that already between 300 and $400 \mathrm{~K}$ some damage recovery occurred. Both the deuterium concentration in the damage peak and the total amount of deuterium trapped in the damaged layer decrease monotonically with pre-annealing temperature. This annealing effect is already observed at the lowest temperatures. At $1150 \mathrm{~K}$ about $70 \%$ of the initially created damage has disappeared, but about $30 \%$ remaining damage is still present.

Thermal desorption spectra of the samples are shown in Fig. 4. The spectra show 2 broad peaks with maxima at about $680 \mathrm{~K}$ and about $820 \mathrm{~K}$. The intensities of both peaks were determined by fitting two Gaussian distributions to the TPD spectra, the relative intensities of 
both peaks as function of the pre-annealing temperature are shown in Fig. 5. The relative intensities change only little in the temperature range from $400 \mathrm{~K}$ to $1000 \mathrm{~K}$, with a small increase of the contribution of the high-temperature peak compared to the low-temperature peak. The shape of the spectra remains almost unaffected by the pre-annealing, only the total inventory decreases as shown in Fig. 3. Only by pre-annealing at $1150 \mathrm{~K}$ the area of the desorption peak at $680 \mathrm{~K}$ decreases significantly faster as compared to the area of the $820 \mathrm{~K}$ peak, see Fig. 5. The temperature shift of the position of the desorption maximum by $\pm 16 \mathrm{~K}$ for the low-temperature peak appears in the temperature range where our temperature measurement has its largest uncertainty of about $\pm 15 \mathrm{~K}$. This shift therefore should not be overinterpreted

Our results are in qualitative agreement with the results presented in [8], where the preannealing time was 2 hours and plasma-loading was at $470 \mathrm{~K}$ at higher energies with $60 \mathrm{~V}$ bias. In [8] it was observed that sample annealing in the temperature range $700-1100 \mathrm{~K}$ does not change deuterium retention, and even a small peak was observed in the total retention after annealing at $1000 \mathrm{~K}$ : These two observations cannot be confirmed with the present data. Only a levelling-off of the recovery rate in the temperature range $1000-1150 \mathrm{~K}$ can be concluded.

According to [24] interstitials become mobile in neutron-irradiated $\mathrm{W}$ in the temperature region from $400-720 \mathrm{~K}$ (stage $\mathrm{III}$ ), from 720 - $920 \mathrm{~K}$ a recovery region of unknown origin is observed, and from $920-1220 \mathrm{~K}$ recovery of vacancies occurs. This interpretation was revised later, and it was concluded that stage III recovery is attributed to vacancy migration [25]. Based on these findings recent workconcluded for tungsten, that from $520-770 \mathrm{~K}$ single vacancies diffuse through the material and can agglomerate with vacancy-like defects to form larger defects or annihilate at sinks like grain boundaries [27]. Based on these observations it was speculated in [8] that annealing from $400-720 \mathrm{~K}$ may be associated with 
the migration of single vacancies to small clusters, while the annealing stage from $720-1150$ $\mathrm{K}$ may be associated with vacancy cluster migration, annihilation and coalescence. The TPD spectra shown in Fig. 4 show only little change of their shape until $1000 \mathrm{~K}$. One might speculate that the small decrease of the low-temperature peak (see Fig. 5) may be connected with the annihilation of single vacancies. However, if single vacancies play an important role in the total hydrogen retention and annihilate at temperatures below $1000 \mathrm{~K}$, then a larger effect would be expected. This makes annihilation of single vacancies unlikely at temperatures below $1000 \mathrm{~K}$. However, this conclusion is only valid if vacancies are not populated with multiple hydrogen atoms with multiple energies and if single vacancies play an important role in the total hydrogen retention.

\section{Summary and conclusions}

Radiation defects were created in recrystallized tungsten by $20 \mathrm{MeV}$ tungsten ions implantation at room temperature to a maximum damage level of $0.9 \mathrm{dpa}$. The samples were then annealed to temperatures of 400 to $1150 \mathrm{~K}$ for 1 hour in order to anneal the created defects. After the annealing procedure the remaining defects were decorated with $\mathrm{D}$ by exposing them to a low-energetic ECR-plasma at floating potential at $400 \mathrm{~K}$ to a fluence of $1 \times 10^{25} \mathrm{D} / \mathrm{m}^{2}$. Retained deuterium was detected by nuclear reaction analysis and temperature programmed desorption. Annealing of defects is observed already at slightly elevated temperatures of $550 \mathrm{~K}$. From $400 \mathrm{~K}$ to $820 \mathrm{~K}$ about $50 \%$ of the defects were annealed, while still about $30 \%$ of the defects were present after annealing at $1150 \mathrm{~K}$.

For DEMO and to some extent already for ITER the retention of tritium in tungsten is expected to be dominated by retention in neutron-induced radiation damage. We showed that some fraction of this damage can be annealed at elevated temperatures. However, a substantial decrease of the defect concentration (by one order of magnitude or more) requires 
annealing to temperatures well above $1150 \mathrm{~K}$. While this may be an option for the DEMO divertor, such high temperatures seem unrealistic for the main chamber wall. The results from [8] indicate that damaging at room temperature followed by subsequent annealing and damaging at elevated temperatures create comparable defect concentrations. Nevertheless, more work is needed for a full understanding of radiation defect creation and defect recovery in tungsten at elevated temperatures. 


\section{Acknowledgements}

The authors would like to thank T. Dürbeck for his assistance with the TESS measurements and J. Dorner and M. Fußeder for their assistance with tungsten ion implantation and ion beam analysis.

This work was supported by the Impuls- und Vernetzungsfonds of the Helmholtz Society, grant HRJRG-216. It received funding from the Euratom research and training programme 2014-2018. 


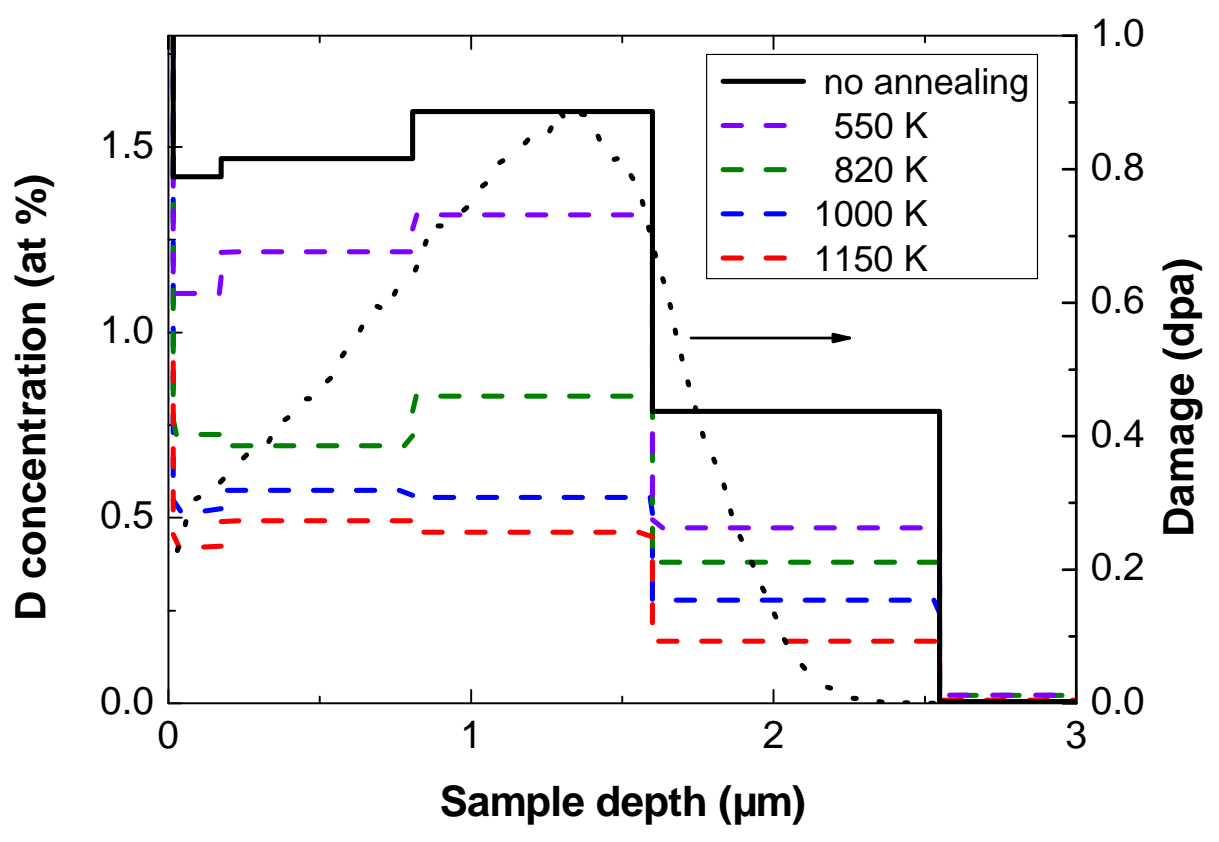

Fig. 1: Deuterium depth profiles after damaging to a maximum damage level of 0.9 dpa at room temperature and subsequent annealing of the sample to the given temperature for 1 hour. Deuterium was implanted to a fluence of $10^{25} \mathrm{D} / \mathrm{m}^{2}$ at $400 \mathrm{~K}$. The dotted line shows the damage profile according to SRIM simulation. 


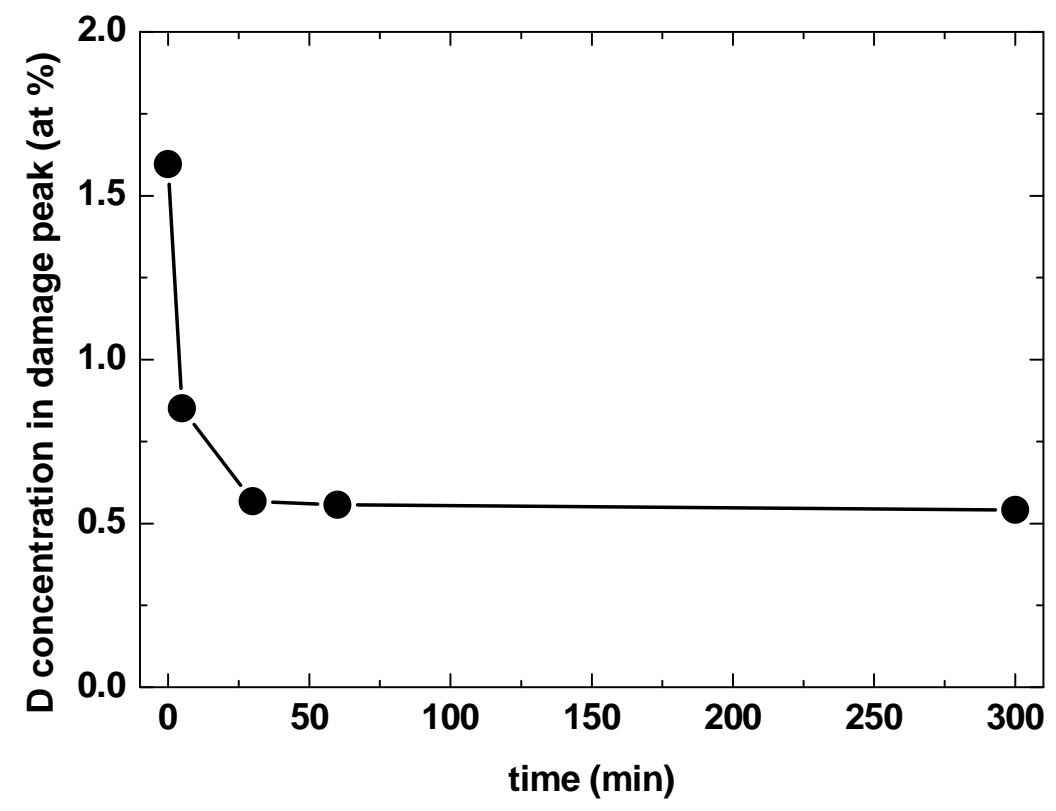

Fig. 2: Deuterium concentration in the damage peak as function of post-annealing time at $820 \mathrm{~K}$. Deuterium was implanted to a fluence of $10^{25} \mathrm{D} / \mathrm{m}^{2}$ at $400 \mathrm{~K}$. 


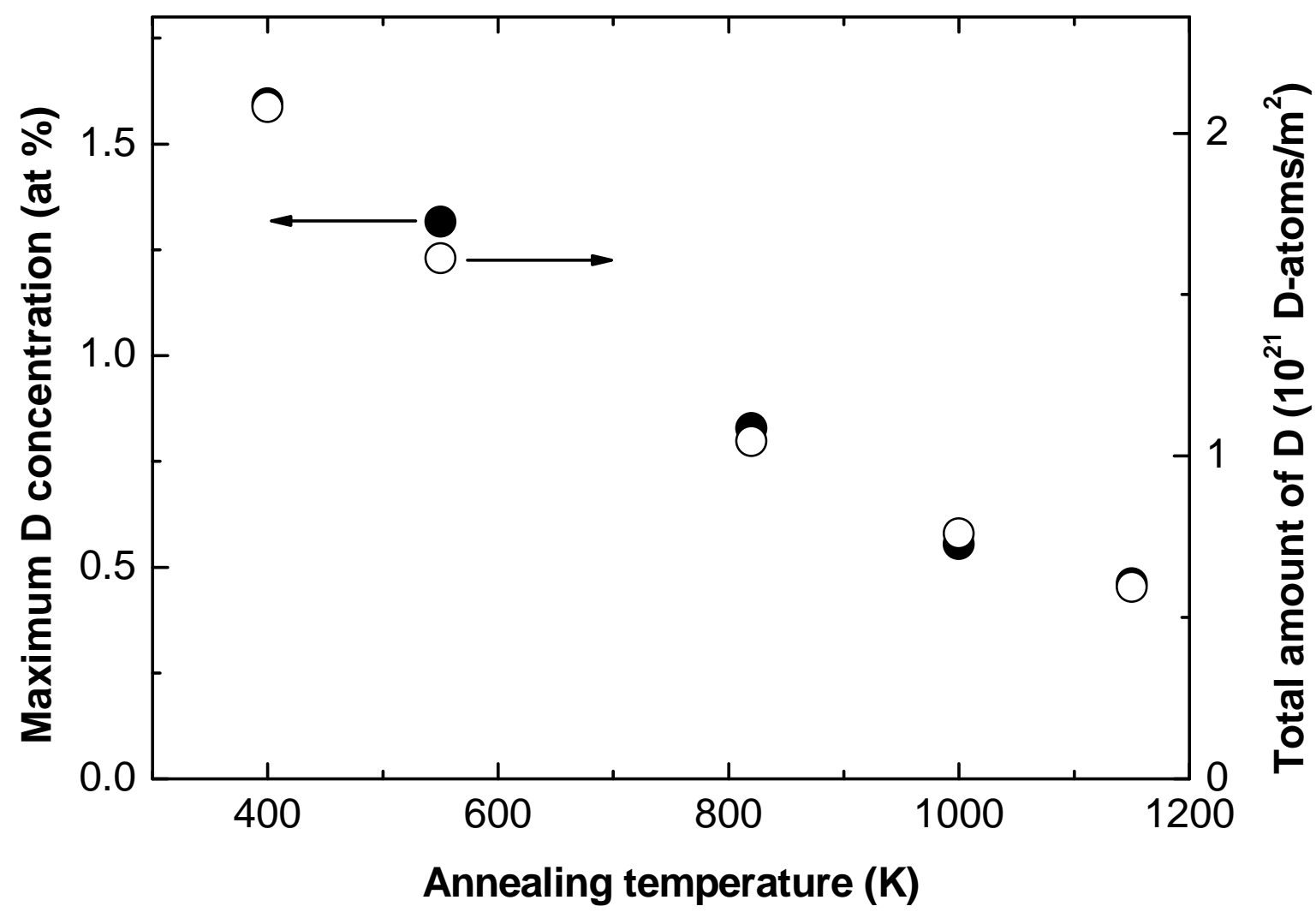

Fig. 3: Deuterium concentration in the damage peak (solid circles) and total deuterium inventory in the damaged layer as derived from NRA (hollow circles) as function of preannealing sample temperature. Deuterium was implanted to a fluence of $10^{25} \mathrm{D} / \mathrm{m}^{2}$ at $400 \mathrm{~K}$. 


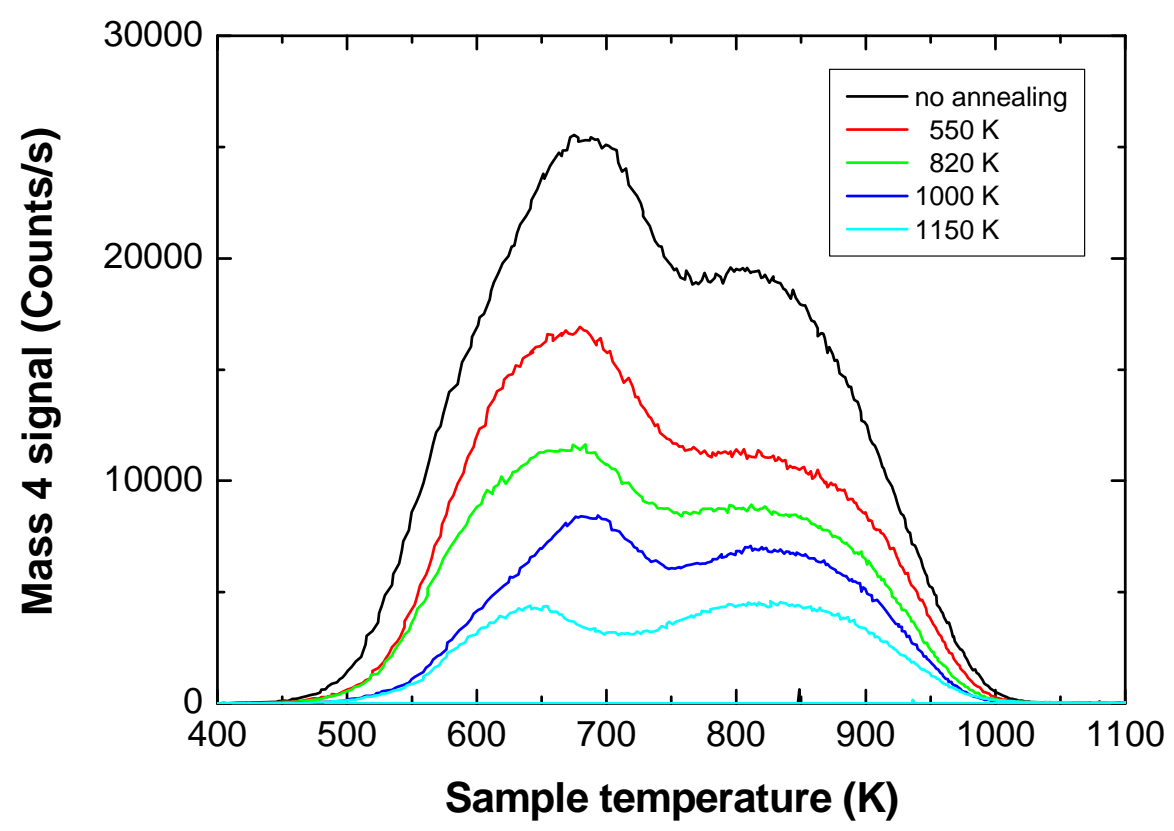

Fig. 4: Thermal desorption spectra of deuterium-implanted $\mathrm{W}$ after damaging to a maximum damage level of 0.9 dpa at room temperature and post-annealing of the sample to the given temperature for 1 hour. The oven heating ramp was $15 \mathrm{~K} / \mathrm{min}$. Deuterium was implanted to a fluence of $10^{25} \mathrm{D} / \mathrm{m}^{2}$ at $400 \mathrm{~K}$. 


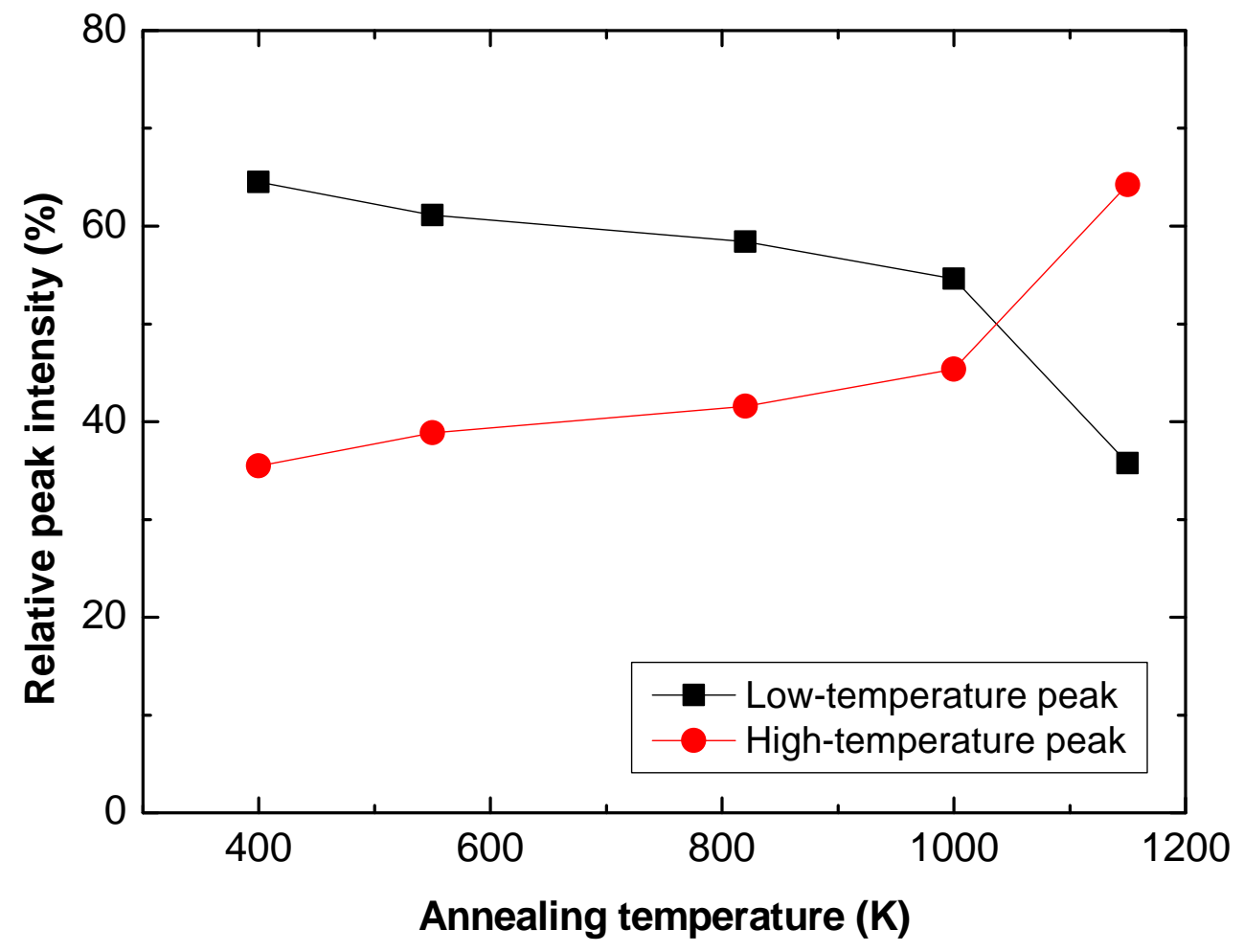

Fig. 5: Relative intensities of the two TPD desorption peaks, see Fig. 4. The low-temperature peak has its maximum at about $680 \mathrm{~K}$, the high-temperature peak has its maximum at about $820 \mathrm{~K}$. 
1 J. Roth, E. Tsitrone, A. Loarte, Th. Loarer, G. Counsell, R. Neu, V. Philipps, S. Brezinsek,M. Lehnen, P. Coad, Ch. Grisolia, K. Schmid, K. Krieger, A. Kallenbach, B. Lipschultz, R. Doerner,R. Causey, V. Alimov, W. Shu, O. Ogorodnikova, A. Kirschner, G. Federici, A. Kukushkin,EFDA PWI Task Force, ITER PWI Team, Fusion for Energy, ITPA SOL/DIV, J. Nucl. Mater. 390-391 (2009) 1

2 M.R. Gilbert, S.L. Dudarev, D. Nguyen-Manh, S. Zheng, L.W. Packer, J.-Ch. Sublet, J. Nucl. Mater. 442 (2013) S755

3 P. Vladimirov and S. Bouffard, C.R. Physique 9 (2008) 303

4 Ł.Ciupiński, O.V.Ogorodnikova, T.Płociński, M.Andrzejczuk, M.Rasiński, M.Mayer, K.J.Kurzydłowski, Nucl. Instr. Meth. B 317 (2013) 159

5 B. Tyburska, V.Kh. Alimov, O.V. Ogorodnikova, K. Schmid, K. Ertl, J. Nucl. Mater. 395 (2009) 150

6 O.V. Ogorodnikova, B. Tyburska, V.Kh. Alimov, K. Ertl, J. Nucl. Mater. 415 (2011) S661

7 M.H.J. 't Hoen, B. Tyburska-Püschel, K. Ertl, M. Mayer, J. Rapp, A. W. Kleyn and P. A.

Zeijlmans van Emmichoven, Nuclear Fusion 52 (2012) 023008

8 O.V. Ogorodnikova, K. Sugiyama, J. Nucl. Mater. 442 (2013) 518

9 A. Manhard, IPP Report 17/34, Max-Planck-Institut für Plasmaphysik, Garching, Germany, (2012)

10 A. Manhard, G. Matern, M. Balden, Praktische Metallographie / Practical Metallography 50 (2013) 5

11 J.F. Ziegler, Nucl. Instr. Meth. B 219 (2004) 1027

$12 \mathrm{http}: / / \mathrm{www}$. srim.org

13 ASTM Int'1 E521-96 Standard Practice for Neutron Radiation Damage Simulation by Charge Particle Irradiation, Annual Book of ASTM Standards vol 12.02 (Philadelphia, PA:

American Society for Testing and Materials) $p 7$

14 A. Manhard, T. Schwarz-Selinger, W. Jacob, Plasma Sources Science and Technology 20 (2011) 015010

15 M. Mayer, E. Gauthier, K. Sugiyama, U. von Toussaint, Nucl. Instr. Meth. B 267 (2009) 506

16 R.A. Langley, S.T. Picraux, F.L. Vook, J. Nucl. Mater. 53 (1974) 257

18 K. Schmid, U. von Toussaint, Nucl. Instr. Meth. B 281 (2012) 64

19 M. Mayer, SIMNRA User's Guide, IPP Report 9/113, Max-Planck-Institut für

Plasmaphysik, Garching, Germany, (1997)

20 W. Möller, F. Besenbacher, Nucl. Instr. Meth. 168 (1980) 111

21 V.Kh. Alimov, M. Mayer, J. Roth, Nucl. Instr. Meth. B 234 (2005) 169

22 E. Salançon, T. Dürbeck, T. Schwarz-Selinger, F. Genoese, W. Jacob, J. Nucl. Mater. 376 (2008) 160

23 M. Mayer, Nucl. Instr. Meth. B 266 (2008) 1852

24 L.K. Keys, J. Moteff, J. Nucl. Mater. 34 (1970) 260

25 H. Schultz, Materials Science and Engineering A141 (1991) 149

27 A. Debelle, M.F. Barthe, T. Sauvage, J. Nucl. Mater. 376 (2008) 216 